\section{Discrepancy between national medical licencing examination content and disease conditions encountered in postgraduate clinical training in Japan}

Medical knowledge is an essential unit of the spectrum of entrustable professional activity for physicians, and knowledge assessment for the certification of medical licencing exists in many countries. To be registered as physicians, Japanese medical students must succeed in the National Medical Practitioners Qualifying Examination (NMPQE), which consists of multiple-choice questions that evaluate competence in basic clinical knowledge needed during the mandatory 2-year residency training. Such training comprises super rotations of internal medicine, emergency medicine, surgery, obstetrics and gynaecology, paediatrics and psychiatry. It is important that qualifying examinations in medicine be validated based on experience acquired in actual clinical practice; for example, the content of the maintenance of certification examination administered by the American Board of Internal Medicine is based on conditions encountered in clinical practice. ${ }^{1}$ However, the validity of the Japanese NMPQE has not yet been evaluated; thus, to specifically identify conditions not covered by the NMPQE, we compared the contents of the NMPQE for the fiscal year 2016 with clinical conditions frequently encountered by physicians during junior residency, that is, clinical training in postgraduate years 1 and 2.

We collected data on conditions encountered by doctors during junior residency in the Urasoe General Hospital and other affiliated hospitals. Thirteen resident physicians had passed the NMPQE for the fiscal year 2016 and had completed the mandatory 2-year junior residency training programme at the Urasoe General Hospital. We identified disease conditions encountered by these residents based on discharge summaries submitted by them to the electronic health records of the training hospitals.

Morphological analysis was used to identify diseases or conditions from discharge summaries and compare them with question items, choices and answers in the NMPQE. In morphological analysis, a sentence is reduced into morphemes,

\title{
Sample Sentence
}

He got the flu. (In English)
彼はインフルエンザに䍜った。(In Japanese)
Morphological analysis

(He)

(the flu)

(got)

(.)

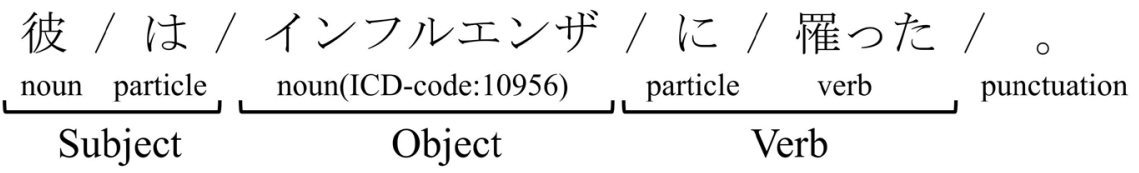

Figure 1 Representative sample morphological analysis for extracting clinical conditions from Japanese literature. Morphological analysis is a process of breaking down a sentence into morphemes, that is, the smallest unit of language with meaning, and determining their grammatical attributes (eg, parts of speech and conjugated forms). All disease conditions registered in the MANBYO dictionary (MANBYO_201907_Dic-utf8.dic), a medical dictionary for MeCab, are given International Classification of Diseases codes and can be morphologically identified as disease conditions. Morphemes were extracted as names of diseases and were verified by the Japanese Nanzando's Medical Dictionary (http://www.nanzando.com/ books/850231.php).

and their grammatical attributes (eg, parts of speech and conjugated forms) are determined. Disease conditions not mentioned in the NMPQE but encountered at least 10 times in the discharge summaries were listed; conditions encountered in outpatient settings were excluded by two general internal medicine specialists. A representative illustration of morphological analysis is provided in figure 1 .

We identified 8016 disease conditions listed in discharge summaries, while only 5572 disease conditions were included in the NMPQE. Table 1 lists the disease conditions $(n=20)$ that were not mentioned in the NMPQE but were listed at least 10 times in the discharge summaries.

Our results suggest that the NMPQE did not cover several disease conditions commonly encountered by junior residents, although the fundamental aim of the junior residency training programme is acquiring basic clinical competency on common diseases, integrating clinical knowledge and skills, and applying these to patients as needed. For instance, hip fracture did not appear in the NMPQE; nevertheless, it is a common condition among elderly Japanese patients that must be comanaged by hospitalists or internists with orthopedists to ensure the quality and safety of treatment. Moreover, the NMPQE did not cover important differential diagnoses of certain diseases; for example, necrotising fasciitis (NF) was included in the NMPQE (data not shown), whereas cellulitis, which should be part of the differential diagnosis for NF, was not mentioned in the examination. These results suggest that the NMPQE did not provide due importance to common differential diagnoses, which may lead to discrepancies between knowledge

Table 1 Diseases/conditions and their frequency in discharge summaries (10 times or greater) that were absent in the National Medical Practitioners Qualifying Examination for the fiscal year 2016

\begin{tabular}{ll}
\hline Disease & Frequency \\
\hline Hip fracture & 74 \\
\hline Knee osteoarthritis & 45 \\
\hline Paroxysmal atrial fibrillation & 45 \\
\hline Lacunar infarction & 35 \\
\hline Acute cholecystitis & 33 \\
\hline Acute bronchitis & 33 \\
\hline Bacteraemia & 21 \\
\hline Putamen haemorrhage & 18 \\
\hline Cancer pain & 17 \\
\hline Alcoholic cirrhosis & 16 \\
\hline Renal anaemia & 14 \\
\hline Pseudogout & 14 \\
\hline Infectious enteritis & 12 \\
\hline Cholangiocarcinoma & 11 \\
\hline Cellulitis & 11 \\
\hline Neurogenic bladder & 11 \\
\hline Internal carotid artery stenosis & 11 \\
\hline Clavicle fracture & 11 \\
\hline Sick sinus syndrome & 10 \\
\hline Hypoxic encephalopathy & 10 \\
\hline
\end{tabular}


required for graduating medical school and common conditions encountered by junior residents during postgraduate training.

With progress in the internationalisation of healthcare workers, including physicians, the quality of practice and medical education for medical professionals need to be warranted. ${ }^{2}$ The World Federation for Medical Education (WFME) has proposed a framework for a global standard of quality improvement in medical education, and the importance of clinical knowledge is mentioned as an important component. ${ }^{3}$ In the UK, the General Medical Council plans to implement the UK Medical Licensing Assessment, a large-scale licencing examination for medical graduates. This initiative aims to collect data about the deviation of quality of performance related to differences in the unique curricula of medical colleges. ${ }^{4}$ Although the causal evidence should be identified, a higher score on a large-scale licencing examination and better clinical performance may be correlated. ${ }^{5}$ Thus, the validity of a licencing examination can be crucial for assessing clinical performance. Clinical knowledge needs to be validated in this context, and our methodology for assuring content validity may be useful for assessing consistency between clinical practice and the educational content that is covered in a licencing examination. Further, the WFME stresses the importance of local needs and the context of each nation when implementing the framework. ${ }^{3}$ Assessing content validity in each nation may be warranted, and theoretically, morphological analysis in various languages may be useful. This can be implemented for countries that have their own national medical licencing examination.

The present study is limited by selection bias as the residents belonged to a single hospital programme. Further, we analysed the NMPQE of only a single year.

In conclusion, the medical licencing examination in Japan appears to not include several disease conditions commonly encountered by junior residents during postgraduate training. Concordance between the NMPQE and conditions encountered during junior residency should be enhanced to comprehensively cover common diseases encountered during junior residency training.

\section{Tomoharu Suzuki $\odot{ }^{1}{ }^{1}$ Koshi Kataoka, ${ }^{2}$ Yuji Nishizaki $\odot$, 2,3 Shinji Kono, ${ }^{4}$ Yasuharu Tokuda ${ }^{5}$}

${ }^{1}$ Hospital Medicine, Urasoe General Hospital, Urasoe, Japan

${ }^{2}$ Division of Medical Education, Juntendo University School of Medicine, Tokyo, Japan

${ }^{3}$ Medical Technology Innovation Center, Juntendo University, Tokyo, Japan

${ }^{4}$ Department of Computer and Information Sciences, Ibaraki University, Hitachi, Japan

${ }^{5}$ Muribushi Okinawa Center for Teaching Hospitals, Okinawa, Japan

Correspondence to Dr Yuji Nishizaki, Division of Medical Education, Juntendo University School of Medicine, Tokyo 113-8421, Japan;

ynishiza@juntendo.ac.jp

Twitter Tomoharu Suzuki @TomoharuHM

Acknowledgements The authors thank Enago ( www.enago.jp) for English language review.

Contributors TS, KK and YN designed this study in whole and drafted the manuscript. TS and YN contributed to data collection. SK contributed to statistical analyses in this study. All authors contributed to provide advice on the interpretation of the results. YT revised the manuscript critically for important intellectual content and approved finally the manuscript submitted. All authors read and approved the final manuscript.

Funding The authors have not declared a specific grant for this research from any funding agency in the public, commercial or not-for-profit sectors.

Competing interests None declared.

Patient consent for publication Not required.

Provenance and peer review Not commissioned; internally peer reviewed.

\section{(2) \\ OPEN ACCESS}

Open access This is an open access article distributed in accordance with the Creative Commons Attribution Non Commercial (CC BY-NC 4.0) license, which permits others to distribute, remix, adapt, build upon this work non-commercially, and license their derivative works on different terms, provided the original work is properly cited, appropriate credit is given, any changes made indicated, and the use is non-commercial. See: http:// creativecommons.org/licenses/by-nc/4.0/.

(c) Author(s) (or their employer(s)) 2021. Re-use permitted under CC BY-NC. No commercial re-use. See rights and permissions. Published by BMJ.

D Check for updates

To cite Suzuki T, Kataoka K, Nishizaki Y, et al. Postgrad Med I Epub ahead of print: [please include Day Month Year]. doi:10.1136/ postgradmedj-2021-140920

Accepted 13 August 2021

Postgrad Med J 2021;0:1-2.

doi:10.1136/postgradmedj-2021-140920

ORCID iDs

Tomoharu Suzuki http://orcid.org/0000-0002-55570516

Yuji Nishizaki http://orcid.org/0000-0002-6964-6702

\section{REFERENCES}

1 Gray B, Vandergrift J, Landon B, et al. Associations between American Board of internal medicine maintenance of certification status and performance on a set of healthcare effectiveness data and information set (HEDIS) process measures. Ann Intern Med 2018;169:97-105.

2 Karle H. Global standards and accreditation in medical education: a view from the WFME. Acad Med 2006;81:543-8.

3 Education WFFM. Basic medical education WFME global standards for quality improvement, 2020. Available: https://wfme.org/wp-content/uploads/2020/12/WFMEBME-Standards-2020.pdf [Accessed 7 Jul 2021].

4 Rutter-Locher Z, Menzies-Wilson R. What is the role for a licensing examination in the UK? Clin Teach 2018;15:511-2.

5 Archer J, Lynn N, Coombes L, et al. The impact of large scale licensing examinations in highly developed countries: a systematic review. BMC Med Educ 2016;16:212. 